\title{
INVESTIGACIONES
}

\section{Formación ética del profesional y ética profesional del docente}

\author{
Professional's ethical formation and professional ethics of the professor
}

\author{
Gerardo Ramos Serpa ${ }^{a}$, Adriana López Falcón ${ }^{a}$ \\ ${ }^{a}$ Universidad Regional Autónoma de Los Andes, Ecuador. Universidad de Matanzas, Cuba. \\ gramosserpa@gmail.com, alopezfalcon1@gmail.com
}

\begin{abstract}
RESUMEN
La sociedad actual presenta carencias significativas en la ética del comportamiento de los individuos, lo que se expresa también en el campo de la educación y demanda en el caso de la educación superior atender la formación ética de los profesionales. El presente estudio posee como objetivo fundamentar la naturaleza y papel de la formación ética del profesional como parte de su formación integral y la relevancia de la ética profesional del docente para contribuir a ello. A partir de un enfoque cualitativo y del análisis documental de contenido se concluye que la formación ética del profesional representa un elemento esencial de la integralidad y la calidad de un profesional efectivamente apto para enfrentar y resolver las demandas y los retos de la actualidad, a la vez que el docente que lo forme debe poseer una ética profesional que lo distinga como profesional de la educación.

Palabras claves: educación superior, ética, formación del profesional, profesionalización docente.
\end{abstract}

\begin{abstract}
The current society presents significant lacks in the ethics of the behavior of the individuals, that expresses itself also at the educational field and demand in the case of higher education attend to the ethical formation of the professionals. The present study possesses as objective to base the nature and role of the professional's ethical formation as part of its integral formation and the relevance of the professional ethics of the professor to contribute it. Starting from a qualitative approach and of the documental analysis of content it is been concluded that the professional's ethical formation represents an essential element of the integrity and the quality of a really apt professional to confront and to solve the demands and the challenges of the present time, at the same time that the professor that forms it should possess a professional ethics that distinguishes it as educational professional.

Keywords: higher education, ethics, professional's formation, teaching profesionalization.
\end{abstract}




\section{INTRODUCCIÓN}

Existe un entrecruzamiento y relación real efectiva entre la sociedad, la ética y la educación, lo que en el caso específico de la educación superior se expresa de manera peculiar en la necesaria ética profesional que debe ser formada y promovida como parte de la formación integral de cualquier profesional.

La actitud y formación ética del profesional requiere al menos de tres elementos: claridad conceptual, responsabilidad y compromiso.

La relación entre ética y sociedad constituye una cuestión de acuciante actualidad y necesidad de ser entendida y atendida.

Muestra de esto lo constituye el propio contenido de los llamados Objetivos de Desarrollo Sostenible, los cuales, sin tener un objetivo específico dedicado solo o exclusivamente a "lo ético", demuestran que en todos ellos se encuentra presente y actuante el componente o la dimensión ética de los mismos.

Baste solo resaltar que en objetivos tales como el de alcanzar para el año 2030 el fin de la pobreza, el hambre cero, la igualdad de género, el trabajo decente, la reducción de las desigualdades, la producción y el consumo responsables, o el referido a la paz y la justicia, por solo nombrar algunos, se evidencia y muestra con toda su fuerza y actualidad la irrenunciable e indispensable dimensión ética del accionar humano que tanto a nivel individual como social está llamada a atender y lograr la sociedad actual para alcanzar las metas y niveles necesarios para su desarrollo perspectivo.

Como expresara el exsecretario General de las Naciones Unidas:

Nuestro mundo globalizado se caracteriza por avances extraordinarios junto con niveles inaceptables e insostenibles de miseria, temor, discriminación, explotación e injusticia y un comportamiento irresponsable respecto del medio ambiente en todos los planos. Sin embargo, también sabemos que estos problemas no son accidentes de la naturaleza ni son productos de fenómenos ajenos a nuestro control. Son consecuencia de acciones y omisiones de las personas... (Ki-moon, 2014, p. 5),

lo que señala en la dirección de las falencias en cuanto a la responsabilidad y comportamiento no ético de los individuos y grupos sociales en su accionar.

En igual sentido, y destacando la incidencia del sistema social prevaleciente en los males que hoy aquejan a nuestra sociedad, personalidades tan disímiles como Bill Gates y el Papa Francisco han considerado, respectivamente, que "los altos niveles de desigualdad son un problema... inclinando las democracias en favor de poderosos intereses y socavando el ideal de que todas las personas son creadas iguales" (Gates, 2014), así como que:

¿Reconocemos que las cosas no andan bien en un mundo donde hay tantos campesinos sin tierra, tantas familias sin techo, tantos trabajadores sin derechos, tantas personas heridas en su dignidad? ¿Reconocemos que las cosas no andan bien cuando estallan tantas guerras sin sentido y la violencia fratricida se adueña hasta de nuestros barrios? ¿Reconocemos que las cosas no andan bien cuando el suelo, el agua, el aire y todos los seres de la creación están bajo permanente amenaza?... Hay, sin embargo, un hilo invisible que une cada una de esas exclusiones, ¿podemos reconocerlo? Porque no se trata de cuestiones aisladas. Me pregunto si somos capaces de reconocer que estas 
realidades destructoras responden a un sistema que se ha hecho global (Francisco, 2015).

Valga solo como muestra en el plano económico el hecho de que el $82 \%$ de la riqueza mundial producida en el año 2017 fue a parar a manos del 1\% de la población ya más rica del planeta (Oxfam, 2018, p. 10), lo que evidencia no solo una cuestión técnica ni puramente económica o financiera sino los fundamentos y procedimientos antiéticos en los que se asienta la distribución de las riquezas que salen de las manos de los muchos que trabajan y van a parar a las de los pocos que se favorecen.

De igual modo en la esfera específica de la educación superior se han señalado limitaciones y tendencias negativas asociadas a fenómenos tales como a las disparidades entre las diferentes regiones del mundo, países y al interior de los mismos en cuanto al acceso a este nivel educacional y en particular a las instituciones de alta calidad (UNESCO, 2017, p. 191), a la vez que dicha educación "se concibe cada vez más como un artículo de consumo internacional respaldado por tratados comerciales" (UNESCO, 2017, p. 188), deformando con ello su naturaleza y fin esencial.

Todo lo anterior subraya la necesidad de atender los aspectos éticos en la sociedad actual, el papel en ello de la educación y en especial de la educación superior, en este caso a través de la necesaria e imprescindible formación ética que se le debe propiciar a todo profesional, a lo que va unido tanto la preparación como la integridad propiamente ética de los docentes que en esto participan e indicen.

Ponderada y autocríticamente se ha considerado que:

Las universidades y las escuelas normales, en especial los académicos, no somos culpables de todas las decisiones y prácticas no éticas de los egresados de la educación superior; sin embargo, la influencia formativa y sistemática de los profesores se sitúa como un tema que merece estudiarse... (Hirsch y López, 2014, p. 311).

En relación con la educación superior, diversos estudios recientes han señalado limitaciones y deformaciones en cuanto a la ética profesional del docente, entre ellas el plagio, la producción de artículos en serie, la mala utilización del financiamiento para la investigación y la asesoría de tesis sobre temas desconocidos para el tutor, entre otros (Pérez-Castro, 2017).

Tales indagaciones han llegado incluso hasta el abordaje de una temática tan actual y presente como el de las aproximaciones éticas en relación con el uso de las tecnologías de la información y la comunicación en la educación superior (García, Gutiérrez, Mujica y Henríquez, 2016), sus potencialidades y desaciertos.

De aquí que el presente estudio se propone como objetivo fundamentar la naturaleza y papel de la formación ética del profesional de nivel superior como parte de su formación integral y la relevancia de la ética profesional del docente para contribuir acertadamente a esto.

\section{METODOLOGÍA}

Se realiza una investigación descriptiva, con un enfoque cualitativo y un paradigma sociocrítico que pretender ofrecer valoraciones y elementos a ser tomados en consideración 
para el cambio y la mejora de las políticas y normativas educacionales, así como para el perfeccionamiento de la preparación y el comportamiento de los docentes.

Se emplearon en particular los métodos de análisis documental de contenido (Pinto y Gálvez, 1996; López, 2002), así como el analítico-sintético (Behar, 2008; Lopera, 2010), con la finalidad de precisar a partir de diversos puntos de vista y su valoración crítica, la relevancia de la formación ética del profesional y la contribución en ello de la ética profesional del docente.

\section{RESULTADOS}

\subsection{MORAL Y ÉTICA COMO REFERENTES CONCEPTUALES DE LA FORMACIÓN ÉTICA Y LA ÉTICA PROFESIONAL}

Se hace necesaria una precisión conceptual acerca de los términos de moral y de ética. Los mismos, fuera del lenguaje cotidiano y ya en el ámbito científico y académico, son entendidos de muy diversas maneras. Es preciso delimitar que por moral se entiende una forma específica de actividad humana, a la vez que la ética se asume como la disciplina científica de carácter filosófico que estudia la moral.

Lo anterior exige ser concretado y contextualizado a partir de la comprensión general de la actividad humana como el modo específicamente humano mediante el cual el sujeto existe y se vincula con los objetos y procesos que le rodean, a los que transforma en el curso de la misma, lo que le permite a su vez modificarse a sí mismo y edificar el propio sistema de relaciones sociales en el que desenvuelve su vida; y del reconocimiento de un conjunto de rasgos esenciales a ella asociados, tales como su carácter social, su adecuación a fines, el poseer objetivos orientadores, su modo consciente de planearse y ejecutarse, su carácter universal, el reconocimiento de sus lados material e ideal como parte de su estructura sustancial, a la vez que sus lados objetivo y subjetivo como parte de su estructura funcional, la existencia de un sujeto y un objeto de toda actividad humana, de su naturaleza autorregulada, y de la existencia de variadas formas fundamentales de existencia de dicha actividad humana, es que se puede entonces comprender a la actividad moral como un tipo peculiar de actividad humana.

Así vista, la actividad moral constituye la forma fundamental de actividad y dimensión del ser humano dirigida a la regulación del comportamiento de los sujetos en correspondencia con los significados e implicaciones de las acciones para los demás, a través de un conjunto de normas y preceptos socialmente aceptados.

La estructura fundamental de la actividad moral se encuentra constituida por la práctica moral y la conciencia moral. A la práctica moral como conjunto de acciones materiales que conducen a la transformación de la realidad y del propio sujeto desde el ángulo de su significación para la regulación del comportamiento de los individuos y grupos en la sociedad, se asocian fenómenos tales como la conducta moral, la elección moral y el conflicto moral. A su vez, a la conciencia moral como reflejo ideal en la conciencia del sujeto de las acciones materiales que los mismos desenvuelven, se vinculan fenómenos tales como los conocimientos morales, las valoraciones morales y las emociones morales.

Tanto la práctica moral como la conciencia moral constituyen una unidad indisoluble y dos lados necesarios e interdependientes de toda actividad moral, seamos más o menos conscientes de esto. 
La actividad moral como forma fundamental de la actividad humana se encuentra asociada a relevantes fenómenos propios de la misma, tales como el ideal moral, la norma moral, los principios morales, los valores morales, la valoración moral, el bien y el mal, el deber ser, la responsabilidad, el sentido de la vida, la amistad, la felicidad, entre otros muchos, los cuales son distintivos de la existencia humana y de la naturaleza específica de los seres humanos. La actividad moral desempeña como funciones fundamentales la de carácter regulador, la valorativo-orientadora, la cognoscitiva y la ideológica. Precisamente, a través del amplio y variado sistema de influencias que envuelven la vida de los seres humanos en sociedad, y que van desde la familia, pasando por los medios de comunicación, hasta las relaciones personales que establece cada individuo, es que se conforma el comportamiento y la conciencia moral de los mismos. Entre tales factores, la educación desempeña un papel significativo, lo que se expresa en la función de formación ética de la educación en general y sus peculiaridades en la formación de profesionales de nivel superior.

\subsection{FORMACIÓN ÉTICA DEL PROFESIONAL}

La calidad e integralidad en la formación de todo profesional, ya sea del área de las ciencias exactas, técnicas o socio-humanística, supone al menos dos grandes componentes: uno técnico -específico del área del saber y del desempeño de cada rama profesional-; y otro humanístico -propio de cualquier individuo como ser humano y social-.

La formación humanística está llamada a contribuir y aportar a la formación integral de todo tipo de profesional a través de un relevante, significativo e insustituible conjunto de funciones básicas que solo ella se encuentra en capacidad de ofrecerle a un profesional para poder hablar de la calidad e integralidad de la formación de este.

Tales funciones básicas de la formación humanística son:

- Función de formación económica.

- Función de formación política.

- Función de formación intelectual-cognoscitiva.

- Función de formación estética.

- Función de formación patriótico-nacional.

- Función de formación axiológica.

- Función de formación emocional.

- Función de formación cosmovisiva.

Sobre la base de tales funciones básicas o esenciales la formación humanística desempeña además otras funciones, entre ellas:

- Función de formación ciudadana.

- Función de formación ambiental.

- Función de formación jurídica.

- Función de formación para la investigación.

- Función de formación para la diversidad.

- Función de formación para la paz.

Entre las funciones básicas de la formación humanística se encuentra la función de formación ética. La misma contribuye a la elaboración y asimilación de las normas 
y patrones de conducta que regulan la convivencia y las relaciones de los sujetos en la sociedad, inculcando un sistema de principios humano-universales e histórico-concretos en el comportamiento social de la persona.

De aquí que la formación ética del profesional representa la concreción y contribución de lo ético a la integralidad de un profesional en correspondencia con las demandas y retos de la sociedad actual como parte inalienable de su preparación y desempeño en el plano de los valores y normas que regulan su comportamiento y valoraciones, tanto en la esfera específica de su quehacer profesional como de su vida personal y social.

\section{3. ÉTICA PROFESIONAL DEL DOCENTE}

Dedicarse a la profesión docente no es solo una cuestión de oportunidad de empleo, o de poseer y mostrar una titulación en dicha rama, sino supone un compromiso y una serie de competencias para esta actividad. Entre los componentes que hacen de un profesional el ser un profesional de la docencia se encuentra, precisamente, su ética profesional.

Una profesión es aquella forma especial de organización ocupacional basada en un cuerpo de conocimiento sistemático adquirido a través de una formación educativa. Ella es el resultado de una formación profesional especializada. Dicha formación se concibe como el conjunto de procesos sociales de preparación y conformación del sujeto referido a fines precisos para un posterior desempeño en el ámbito laboral. En un sentido, la ética profesional puede entenderse como la disciplina científica que se ocupa de formular, determinar y regular el conjunto de responsabilidades morales o reglas de acción necesarias para el ejercicio de una profesión. En otra dirección, la ética profesional se concibe como aquel rasgo distintivo de una profesión vinculado al deber moral profesional y que expresa los mandatos y obligaciones que pretenden guiar éticamente la acción del profesional en su desempeño, lo que a su vez se ve reflejado también en su comportamiento individual y social como una integralidad. La ética profesional como paradigma o deber ser esperado se contrapone a transgresiones y problemas éticos profesionales fundamentales que pueden ser reconocidos y desafortunadamente se encuentran con frecuencia. Entre ellos se pueden nombrar el abuso de poder, los conflictos de intereses, el nepotismo, el soborno, la lealtad excesiva, la falta de dedicación y compromiso, el abuso de confianza, el encubrimiento de lo mal hecho, el egoísmo, la incompetencia, entre otros. Ante ellos, se deben enarbolar, aplicar y hacer prevalecer un amplio espectro de valores éticos profesionales que poseen una alta significación positiva para cualquier profesión, entre los que se han destacado como fundamentales la autonomía, la responsabilidad y la competencia profesional (Hirsch, 2003).

La ética en cualquier profesión se expresa en diversos y variados planos, entre los que se pueden reconocer la significación y muestra de la ética profesional ante la ley, ante los derechos humanos, ante el medio ambiente, ante las futuras generaciones, ante la comunidad, ante la organización en que se labora, ante la propia profesión y ante uno mismo. La ética profesional posee su modo peculiar y su rasgo distintivo en cada profesión. Precisamente, una de ellas es la profesión docente. La ética profesional docente constituye la expresión, compromiso y responsabilidad moral del docente ante su profesión.

$\mathrm{Al}$ respecto se considera que la ética de la docencia se centra en el abordaje y precisión de aspectos tales como los atributos morales del docente, las características que posee el razonamiento moral, la toma de decisiones en este campo, la conducta y el obrar aquí, 
junto a las habilidades del docente para prever las consecuencias de su accionar, entre otros (Gluchmanová, 2017, p. 63).

La ética profesional docente se basa y supone no solo poseer un título o graduación sino una preparación, actitud y dominio de al menos los siguientes campos (Mateo, 2010):

- Dominio de los problemas y cuestiones más acuciantes a enfrentar y resolver de la realidad educativa.

- Dominio de las diversas teorías que permiten explicar y comprender la realidad y proyectar escenarios perspectivos.

- Dominio de la pedagogía como ciencia.

- Dominio del ethos específico de la profesión.

La ética profesional docente se manifiesta, expresa y proyecta en diversos planos o direcciones, tales como con la sociedad, la escuela, los alumnos, los colegas de trabajo y con la propia persona.

La naturaleza ética del profesional de la docencia se vincula estrechamente con fenómenos tales como la vocación que se posea para su ejercicio, la preparación real que se tenga para su desenvolvimiento, la disposición y comprensión de que la misma constituye un servicio social a realizar, así como el reconocimiento y la posesión de valores propios del individuo que ejerce esta labor.

Junto a todo lo anteriormente señalado se hace necesario destacar que la ética profesional del docente existe y se manifiesta en diversas dimensiones, tales como en el propio proceso de enseñanza-aprendizaje, en la investigación educativa, en la gestión educativa y en el vínculo con la comunidad.

\section{DISCUSIÓN}

El componente ético en el marco del Objetivo de Desarrollo Sostenible número 4, dedicado a la educación de calidad, se expresa de manera relevante en su meta 4.7, la que señala:

Para 2030, garantizar que todos los alumnos adquieran los conocimientos teóricos y prácticos necesarios para promover el desarrollo sostenible, entre otras cosas mediante la educación para el desarrollo sostenible y la adopción de estilos de vida sostenibles, los derechos humanos, la igualdad entre los géneros, la promoción de una cultura de paz y no violencia, la ciudadanía mundial y la valoración de la diversidad cultural y de la contribución de la cultura al desarrollo sostenible, entre otros medios (UNESCO, 2015).

Tal prioridad para el avance actual de la sociedad se corresponde directamente y le da continuidad a la misión de la educación superior, asociada a contribuir al desarrollo sostenible y al mejoramiento del conjunto de la sociedad (UNESCO, 1998, p. 3), lo cual de manera directa y clara se enfrenta a la visión distorsionada de la educación superior como mera formación tecnicista de profesionales y regida por leyes mercantilistas como un negocio lucrativo y de élite.

Diversas son las manifestaciones de la actualidad y necesidad de atención al aspecto ético en la educación superior. Muestras de ello se pueden constatar por ejemplo en el 
hecho de que un importante medio de divulgación de lo que ocurre en la educación superior de los Estados Unidos dedicó en su décimo aniversario en el año 2018 su tema central al papel de los valores éticos para lograr un liderazgo transformativo y el papel de las universidades en proveer y formar ese liderazgo ético, incluso en el marco de la ética de los negocios (UWN, 2018).

En dicho país, la Fundación Nacional de la Ciencia ha abierto una convocatoria de financiamiento orientada a cultivar la cultura para la ética en la investigación en el campo de la ciencia, la tecnología, la ingeniería y la matemática (NSF, 2018). En la misma dirección, se creó en dicho país una Comisión Presidencial para el estudio de las cuestiones relativas a la bioética que, entre otras cuestiones, le dedica un espacio importante a la educación ética y bioética en diferentes niveles educacionales, y que ha recomendado para el logro y fortalecimiento de una "alfabetización ética" la integración de la educación ética a lo largo del currículo en todos los niveles educativos para tanto desarrollar la virtud y el carácter moral como para cultivar el razonamiento ético y las habilidades de toma de decisiones, también en específico en la educación superior aplicado a las profesiones (Bioethics Commission, 2016).

A nivel internacional existen instituciones y sitios especializados en temas éticos vinculados a la educación en general y a la de nivel superior, tales como el Center for Engineering Ethics and Society (https://www.nae.edu/26187.aspx) y el Online Ethics Center for Engineering and Science (http://www.onlineethics.org/) de la Academia Nacional de Ingeniería de los Estados Unidos; el National Center for Professional and Research Ethics (http://ethicscenter.csl.illinois.edu/); el Center for the Study of Ethics in the Professions (http://ethics.iit.edu/about) y la Ethics Education Library (http://ethics.iit. edu/eelibrary/about) del Instituto de Tecnología de Illinois; la Cátedra UNESCO sobre Ética y Sociedad en la Educación Superior de la Universidad Técnica Particular de Loja en Ecuador (http://unescoeticayeducacion.utpl.edu.ec/), entre otros muchos.

No obstante, como contrapartida de lo anterior, otros estudios y apreciaciones consideran que en determinados contextos y momentos se ha pretendido "invisibilizar" la ética de las políticas públicas de educación superior (Navarro, 2014).

Junto a esto, en el caso de la educación superior es cada vez más reconocida y reclamada la necesidad de incluir en los currículos universitarios la formación ética (Crisol y Romero, 2014; Méndez, Torres y Camatón, 2018), aunque por otro lado se aprecia que ello sigue siendo aún una asignatura pendiente por lograr efectiva y plenamente (López, 2013; Finkler y Souza, 2017).

Sobre dicha cuestión se manifiestan puntos de vista encontrados referidos a que la formación ética del profesional no es un resultado espontáneo ni automático en el proceso de formación de este, sino que implica tanto una preparación del docente para ello como un compromiso y sentido de responsabilidad ante la misma. Esto indica que el propio docente debe poseer un conjunto de cualidades y actitudes que lo caractericen como un profesional de la docencia. No se puede desenvolver la función de formación ética sin poseer cualidades éticas adecuadas. No se puede dar lo que no se tiene.

Lo anterior evidencia diversas concepciones acerca de en qué consiste la profesión de ser docente. Esta puede entenderse como la actividad de enseñar, o mejor aún, de formar. Por supuesto que en un sentido amplio los únicos que enseñan no son los docentes, ya que también lo hacen los padres, la familia, el círculo de personas con que nos relacionamos en los estudios, en la comunidad, en el trabajo, las experiencias de vida, entre otros. No 
obstante, el docente es aquel sujeto que se dedica profesionalmente a esta actividad de enseñar y formar, y que por esto para ser considerado y actuar consecuentemente como un profesional de dicha actividad debe ser formado y poseer un conjunto específico de competencias de diverso tipo para su adecuado desempeño.

Un estudio clásico cerca del tema señala que las competencias del docente ante las nuevas dinámicas y problemáticas de la sociedad y de la propia actividad educacional serían organizar y animar situaciones de aprendizaje, gestionar la progresión de los aprendizajes, elaborar y hacer evolucionar dispositivos de diferenciación, implicar a los alumnos en sus aprendizajes y en su trabajo, trabajar en equipo, participar en la gestión de la escuela, informar e implicar a los padres, utilizar las nuevas tecnologías, afrontar los deberes y los dilemas éticos de la profesión, así como organizar la propia formación continua (Perrenoud, 2004).

De igual modo, el Proyecto Tuning para América Latina realiza un estudio sobre las competencias profesionales, indicando que las mismas se organizan y estructuran en 27 competencias genéricas comunes a cualquier tipo de profesional (Beneitone et al., 2007, p. 45), entre las cuales identifica el compromiso ético; unido a un grupo de competencias específicas para cada perfil de titulación. En el caso de educación, se plantean 27 competencias específicas (Beneitone et al., 2007, p. 137), entre las que se ubica el educar en valores, formación ciudadana y democracia; asumir y gestionar con responsabilidad su desarrollo personal y profesional en forma permanente; así como la interacción social y educativa con diferentes actores de la comunidad para favorecer los procesos de desarrollo. No obstante, independientemente de su formulación y modo más o menos explícito en que se refieren a lo ético, se puede considerar que todas y cada una de las competencias profesionales del educador poseen una dimensión o componente ético incuestionable, asociado a la responsabilidad, significación e implicaciones de su preparación y accionar educativo para con sus estudiantes y la sociedad.

De manera general, entre las cualidades o competencias del docente se pueden mencionar las competencias pedagógicas, didácticas, comunicativas, de liderazgo, de innovación, en información, de investigación, de gestión, tecnológicas y digitales, ciudadanas y éticas, entre un amplio y variado espectro de las mismas.

La cuestión se complica al tratarse del profesor de educación superior, pues por lo regular se forman profesores como profesionales para los niveles anteriores, pero prácticamente nadie forma a un profesor universitario. Como se ha dicho:

Al docente universitario la universidad les permite desarrollar la competencia profesional de su formación inicial, esta queda articulada estrechamente a la competencia laboral en el campo en el cual fue formado. Este profesional, al incursionar total o parcialmente en la docencia, desarrolla una nueva competencia profesional: la competencia docente.... (Guzmán, Marín y Castro, 2010, p. 42)

Así mismo, amplio debate suscita la cuestión de los planos o esferas en que existe y se expresa la ética profesional del docente, donde en ocasiones se reduce o limita la misma a lo que tiene lugar solo en el salón de clases. En realidad, debe reconocerse que la ética profesional docente se evidencia y muestra tanto en el proceso de enseñanzaaprendizaje, en la investigación educativa, en la gestión educativa, como en el vínculo con la comunidad. 
De este modo, en el proceso de enseñanza-aprendizaje se evidencia la ética profesional del docente asentada en fundamentos tales como la realización de su función docente con estricto apego y respeto a las directrices éticas y los valores morales tanto a nivel individual como social; el comprender a la educación como un derecho humano fundamental que debe ofrecerse a todos por igual y con calidad; la implementación de los programas y cursos de modo que se opongan a la discriminación ya sea por criterios del sexo, de la raza, del estado civil, de la clase social, de las convicciones políticas, por situaciones de discapacidad, por criterios étnicos, religiosos, de orientación sexual o de edad; facilitar y promover el respeto pleno de los derechos humanos, la búsqueda y viabilidad de la libertad, la dignidad y la justicia social; el hecho de percibir y respetar al estudiante desde una perspectiva integral, como un sujeto con múltiples determinaciones de diverso tipo, insertado en una cultura, condicionado y envuelto por elementos y factores socioeconómicos y políticos.

Entre los principios o exigencias éticas que deben ser tomados en consideración por el docente en el acto de enseñar y formar se deben mencionar los referidos al actuar con honradez, desinterés y lealtad; el no participar de modo activo o pasivo en tratos inhumanos o degradantes; mantener y cuidar el respeto a su dignidad ya sea como individuo y como profesional; perfeccionar de manera permanente su preparación docente integral, prescindiendo del empirismo, la improvisación y la repetición cada curso de los mismos contenidos y maneras rutinarias y acomodadas de impartirlos; asistir puntualmente a sus actividades y obligaciones docentes; cuidar de un comportamiento público y privado adecuado y ejemplar; percatarse y ser consecuente con que su labor como docente es un servicio público no lucrativo; así como favorecer y aportar al desarrollo de la personalidad de sus estudiantes, no solo ofreciendo conocimientos sino también contribuyendo a su formación como ciudadanos, preparados para ejercer la democracia, fomentando en ellos la cultura y desarrollando el espíritu de solidaridad humana.

Si hubiese que destacar en un lugar prioritario los relevantes y trascendentes valores éticos de la labor del docente se podrían señalar su competencia profesional, su responsabilidad ante la profesión, a la vez que su compromiso ante la sociedad. Precisamente, tales valores se oponen a las malas prácticas que lastimosamente se encuentran presentes en cierta medida y ocasiones en el desempeño de esta labor, tales como el ausentismo, la apatía académica, el negar o disminuir el papel del alumno, la simulación, la falta de apoyo a los directivos, la resistencia a los cambios, el credencialismo, y la participación en grupos de poder para influir negativamente o en favor de intereses sectoriales o ajenos a la actividad docente; entre otros. Así mismo, la ética profesional del docente se manifiesta y tiene lugar en el plano de la investigación en educación. Entre las bases éticas de la investigación educativa se deben colocar, sin agotarlas, el respeto por la persona, por el conocimiento, por los valores democráticos, por la libertad académica y por la calidad; sin los cuales sería difícil poder realizar y obtener resultados científicos innovadores y pertinentes.

Entre los elementos a destacar en el marco de la ética profesional de la investigación en educación se podrían destacar el tomar en consideración en las publicaciones que sean resultado de una labor compartida el incluir a todos los participantes en la misma y determinar con precisión el grado de responsabilidad y colaboración de cada uno; no exponer o publicar como de autoría propia elaboraciones científicas que no sean de quien las divulga sin hacer referencia y citar la fuente o el autor; deben reconocerse las aportaciones tanto de carácter profesional como no profesional que se realicen en un trabajo de investigación en equipo; se deberá evidenciar de manera directa y explícita el material 
ya sea publicado o no que haya sido tomado en cuenta en la investigación y publicación de sus resultados a través de citas y referencias; en el caso de investigaciones que involucren a personas o fuentes restringidas se debe hacer referencia a las mismas cuando se hayan realizado previamente las consultas y obtenido el consentimiento para esto; los docentes deben reconocer la participación de los estudiantes en las actividades de investigación cuando ello ocurra, incluso como coautores; no debe realizarse la publicación de un mismo trabajo científico elaborándolo de diversas maneras pero con un mismo contenido en diferentes revistas o fuentes de divulgación; para publicar un artículo o resultado científico que ya ha sido publicado se debe previamente obtener el permiso de la primera fuente que lo divulgó o hacer referencia explícita a la misma, según sea el caso.

Otro plano o esfera en la que se manifiesta la ética profesional del docente es la referida a la gestión educativa. Diversos estudios señalan las falencias que aún existen en la llamada ética de gestión en instituciones educativas en general y de nivel superior en particular (Winfield y Topete, 2014; Madrigal y Almuiñas, 2015), destacándose en particular los no adecuados procesos de selección de personal para estas instituciones, el no evaluar lo ético en el desempeño docente, así como la falta de preparación de los directivos para gestionar adecuadamente los procesos educacionales y las influencias negativas en este proceso de la mercantilización de la educación e intereses ajenos a lo propiamente educacional.

Precisamente, constituyen bases éticas en la gestión educacional la honestidad, el compromiso, la veracidad, la confidencialidad, la justicia, la lealtad, la responsabilidad, el respeto, la transparencia, entre otros elementos que deben orientar y servir de guía el accionar ético en ella.

Esto contrarrestaría y permitiría enfrentar las malas prácticas éticas en esta esfera, tales como el autoritarismo, la simulación en la rendición de cuentas, la negación de las normas establecidas, la falta de formación para la gestión misma, el colocar intereses personales por delante de lo académico, hacer uso de las responsabilidades docentes para hacer carrera política, aplicar de forma manipulada las políticas establecidas, el preferencialismo, el individualismo, etc. Un aspecto estrechamente vinculado a la ética profesional del docente es la existencia de los códigos de ética. Los mismos, en cualquier profesión, constituyen aquel conjunto de principios de conducta, derechos, deberes y normas profesionales que surgen y se elaboran por los propios profesionales u organización dada y cuyo cumplimiento se entiende y asume de manera voluntaria.

Dichos principios, regulaciones y valores representan aquellos que una organización profesional considera que son válidos, evidenciando así una manera dada de comprender una profesión específica y a la vez una orientación acerca del modo de llevarla a la práctica.

Los códigos éticos profesionales muestran y recogen el compromiso de una profesión determinada de realizar su labor de un modo moral y digno. Con esto, tales códigos permiten y facilitan la comunicación entre los profesionales y la sociedad, a la vez que contribuyen a la educación de la conciencia moral de tales profesionales.

El objetivo fundamental de los códigos éticos profesionales es el de delimitar desde el punto de vista de su significación ética aquellos comportamientos que deben ser exigidos a los profesionales, aun cuando ello no se encuentre expresado o respaldado en las normas jurídicas.

De aquí que los códigos éticos profesionales recogen y expresan con claridad y precisión los deberes y obligaciones en el ejercicio de dicha profesión, incluyendo tanto normas de prohibición como normas de orientación. De aquí que se puede decir que tales 
códigos desempeñan la función de ejercer un control de calidad sobre la práctica de la profesión. A los códigos de ética profesionales se les denomina también en ocasiones códigos deontológicos, lo que proviene del término deontología, el cual se entiende como el estudio o ciencia de los deberes; de aquí que la deontología profesional se conciba como el estudio de los deberes de cada profesión. Es por ello que los códigos deontológicos pueden incluir aspectos tales como códigos de conducta, los tipos de infracciones que se pueden cometer, cómo recibir y procesar las consultas, propuestas o quejas que se puedan llevar a efecto, los procedimientos para valorar tales infracciones y reclamaciones o planteamientos, así como el sistema de sanciones que a ello corresponda.

Unido estrechamente a los códigos de ética profesionales existen y funcionan los comités de ética, entendidos como entidades de las asociaciones profesionales, organismos e instituciones para difundir y hacer cumplir los códigos y normativas éticas de cada profesión.

En el caso de la educación, los códigos de ética profesionales usualmente norman y regulan los vínculos entre el docente y la sociedad, la institución educativa, los estudiantes, los colegas de trabajo y con el propio profesional docente. En relación con esto se ha insistido en la necesidad de que existan y se elaboren los códigos deontológicos de las profesiones pedagógicas en un sentido amplio, no solo que incluya a los docentes sino también a los directivos, supervisores y otros (Mallart, 2011).

Aunque no en todos los países, muchos de ellos poseen sus propios códigos éticos o deontológicos de la profesión docente. Tal es el caso, por ejemplo, de Código Modelo de Ética para Educadores elaborado por la National Association of State Directors of Teacher Education Certification de los Estados Unidos (NASDTEC, 2015), el que se encuentra estructurado en 5 principios o esferas de incidencia: la responsabilidad hacia la profesión, la responsabilidad por la competencia profesional, la responsabilidad con los estudiantes, la responsabilidad con la comunidad escolar, y el uso responsable y ético de la tecnología. De igual manera, en el caso de España, existe el Código Deontológico de la Profesión Docente, elaborado por el Consejo General de Colegios Oficiales de Doctores y Licenciados en Filosofía y Letras y en Ciencias (Consejo General CODLFLC, 2010), organizado en 6 grupos de compromisos y deberes de los docentes: en relación con el alumnado, con las familias y los tutores de dichos alumnos, con la institución educativa, con los compañeros de trabajo, con la profesión y con la sociedad.

\section{CONCLUSIONES}

Como se ha podido evidenciar, la formación ética de los profesionales no constituye una tarea o responsabilidad de la educación superior de segundo nivel o prioridad, que pueda ser o no atendida, ni que le corresponda únicamente a las carreras o perfiles profesionales de ciencias sociales y humanísticas, ni solo a los docentes de tales materias, sino que las realidades de hoy exigen la preocupación y ocupación en tal dirección como parte de la integralidad y la calidad de un profesional efectivamente apto para enfrentar y resolver las demandas y los retos más acuciantes del mundo actual. No solo con financiamiento y tecnología se puede lograr el avance de la sociedad y el desarrollo sostenible, sino que para ello se hace cada vez más necesario y apremiante el preparar en el plano ético a todos los ciudadanos y en especial a los profesionales. Para esto el docente de hoy debe encontrarse 
científicamente preparado, además de responsablemente impuesto y comprometido con dicha tarea y función inalienable de la educación en los tiempos que corren. Al respecto se ha indicado incisivamente,

la profesionalización de un oficio es una aventura colectiva, pero que se representa también, en una larga medida, a través de las opciones personales de los profesores, sus proyectos, sus estrategias de formación. Tal es la complejidad de los cambios sociales: no son ni la simple suma de iniciativas individuales, ni la simple consecuencia de una política centralizada. (Perrenoud, 2004, p. 144)

Como parte de esa aptitud y actitud, el docente debe contar con una ética profesional que lo distinga y caracterice de manera integral, no solo en las declaraciones sino en su accionar directo en el aula, en su profesión y como parte de la sociedad.

\section{REFERENCIAS BIBLIOGRÁFICAS}

Behar, D. S. (2008). Metodología de la investigación. México D. F.: Editorial Shalom.

Beneitone, P., Esquetini, C., González, J., Marty, M., Siufi, G. y Wagenaar, R. (2007). Reflexiones y perspectivas de la educación superior en América Latina. Informe Final Proyecto Tuning América Latina 2004-2007. Bilbao: Universidad de Deusto. Última visita 12 de septiembre de 2017. Recuperado desde http://tuning.unideusto.org/tuningal/index.php?option=com_docman\& task $=$ docclick \&Itemid $=191 \&$ bid $=54 \&$ limitstart $=0 \&$ limit $=5$.

Bioethics Commission. (2016). Bioethics for every generation. Washington, D. C.: Presidential Commission for the Study of Bioethical Issues. Última visita 3 de octubre de 2018. Recuperado desde https://permanent.access.gpo.gov/gpo73196/PCSBI_Bioethics-Deliberation_0.pdf

Consejo General CODLFLC. (2010). Código deontológico de la profesión docente. Madrid: Consejo General de Colegios Oficiales de Doctores y Licenciados en Filosofía y Letras y en Ciencias. Última visita 27 de marzo de 2017. Recuperado desde http://www.consejogeneralcdl.es/codigodeontologico-de-la-profesion-docente/

Crisol, M. y Romero, M. A. (2014). Práctica docente versus ética docente. Hacia la mejora de la práctica docente a partir de la ética profesional. Journal for Educators, Teachers and Trainers, 5(2), 23-35. Última visita 15 de mayo de 2018. Recuperado desde http\%3A\%2F\%2Fjett.labosfor.com\%2Findex. php\%2Fjett\%2Farticle\%2Fdownload\%2F80\%2F80\&usg=AOvVaw0qIybviOAGBLwF74YzObTR.

Finkler, M. y Souza, F. R. (2017). La dimensión ética de la educación superior en Odontología: un estudio en Brasil. Bordón, 69(4), 35-49. Última visita 6 de noviembre de 2018. Recuperado desde https://dialnet.unirioja.es/descarga/articulo/6122907.pdf

Francisco, Papa (2015). Discurso del Papa en el encuentro con los movimientos populares en Bolivia. Santa Cruz, 9 de julio de 2015. Última visita 2 de noviembre de 2017. Recuperado desde https:// www.aciprensa.com/noticias/texto-discurso-del-papa-el-encuentro-con-los-movimientospopulares-en-bolivia-80606/

García, B., Gutiérrez, C., Mujica, M. y Henríquez, M. A. (2016). Paradojas, contrastes y aproximación ética en el uso de las TIC desde la educación superior. Revista de Estudios y Experiencias en Educación, 15(29), 29-48. Última visita 10 de mayo de 2017. Recuperado desde https://dialnet. unirioja.es/descarga/articulo/5738281.pdf

Gates, B. (2014). Why inequality matters. Blog de Bill Gates, 13 de octubre de 2014. Última visita 25 de mayo de 2018. Recuperado desde http://www.gatesnotes.com/Books/Why-InequalityMatters-Capital-in-21st-Century-Review

Gluchmanová, M. (2017). Ética profesional de los docentes. Prometeica, 14(6), 58-65. Última 
visita 11 de noviembre de 2018. Recuperado desde https://www.prometeica.com/ojs/index.php/ prometeica/article/download/173/158.

Guzmán, I., Marín, R. y Castro, G. (2010). La competencia y las competencias docentes. Synthesis, (55), 38-45. Última visita 8 de diciembre de 2017. Recuperado desde http://www.aufop.com/ aufop/uploaded_files/articulos/1301588498.pdf

Hirsch, A. (2003). Elementos significativos de la ética profesional. Reencuentro, (38), 8-15. Última visita 21 de enero de 2018. Recuperado desde http://www.redalyc.org/pdf/340/34003802.pdf

Hirsch, A. y López, R. (Coord.) (2014). Ética profesional en educación superior. Sinaloa: Universidad Autónoma de Sinaloa. Última visita 5 de julio de 2018. Recuperado desde http:// roderic.uv.es/bitstream/handle/10550/41252/\%C3\%89tica\%20profesional\%20en\%20la\%20 Educaci\%C3\%B3n\%20superior.pdf?sequence=1\&isAllowed=y

Ki-Moon, B. (2014). El camino hacia la dignidad para el 2030: acabar con la pobreza y transformar vidas protegiendo el planeta. Ginebra: Naciones Unidas. Última visita 13 de marzo de 2018. Recuperado desde http://www.un.org/en/ga/search/view_doc.asp?symbol=A/69/700\&referer=h ttp://www.un.org/millenniumgoals/\&Lang=S

Lopera, J. D. (2010). El método analítico como método natural. Nómadas, 25(1), 1-27. Última visita 4 de diciembre de 2017. Recuperado desde http://pendientedemigracion.ucm.es/info/nomadas/25/ juandiegolopera.pdf

López, F. (2002). El análisis de contenido como método de investigación. Revista de Educación, XXI(2), 167-179. Última visita 19 de febrero de 2018. Recuperado desde http://rabida.uhu.es/ dspace/bitstream/handle/10272/1912/b15150434.pdf

López, R. (2013). Ética profesional en la formación universitaria. Perfiles Educativos, XXXV(142), 15-24. Última visita 25 de octubre de 2017. Recuperado desde http://www.eticaprofesionalanahirsch.com.mx/Disco3/2016/44mxperedu2013n142p1001-1052.pdf

Madrigal, B. E. y Almuiñas, J. L. (Coords.) (2015). Ética y liderazgo en instituciones de educación superior latinoamericanas. Guadalajara: Prometeo Editores. Última visita 14 de septiembre de 2018. Recuperado desde https://www.researchgate.net/profile/Berta_Ermila_Torres/ publication/315665307_Etica_y_liderazgo_en_Instituciones_de_Educacion_Superior_ Latinoamericanas/links/59fb6059aca272347a1d8da7/Etica-y-liderazgo-en-Instituciones-deEducacion-Superior-Latinoamericanas.pdf\#page $=239$

Mallart, J. (2011). Hacia una deontología de las profesiones pedagógicas. XII Congreso Internacional de Teoría de la Educación. Universidad de Barcelona, España.

Mateo, L. (2010). Connotaciones sociales de la profesión del maestro. Temas para la educación, (11), Noviembre. Federación de Enseñanza de CC.OO. de Andalucía.

Méndez, C. G., Torres, M. W. y Camatón, S. B. (2018). Importancia de la ética en la educación superior. Dom. Cien., 4(2), 215-223. Última visita 20 de noviembre de 2018. Recuperado desde https://dominiodelasciencias.com/ojs/index.php/es/article/download/802/930.

NASDTEC (2015). Model code of ethics for educators. National Association of State Directors of Teacher Education and Certification. Última visita 24 de septiembre de 2018. Recuperado desde http://www.nasdtec.net/?page=MCEE_Doc

Navarro, J. A. (2014). La ética está ausente en la política pública de educación superior. Revista Universidad Kino, (3), 1-6. Última visita 9 de noviembre de 2017. Recuperado desde https://rei. iteso.mx/bitstream/handle/11117/5322/\%C3\%89tica,+pol\%C3\%ADtica+p\%C3\%BAblica+y+e ducaci\%C3\%B3n+superior.pdf?sequence $=3$

NSF (2018). Cultivating cultures for ethical STEM. Program solicitation. National Science Foundation, April 17, 2018. Última visita 26 de junio de 2018. Recuperado desde https://www. nsf.gov/pubs/2018/nsf18532/nsf18532.pdf

Oxfam (2018). Premiar el trabajo, no la riqueza. Informe de Oxfam 2018. Oxford: Oxfam Internacional. Última visita 5 de agosto de 2018. Recuperado desde https://www.oxfam.org/ sites/www.oxfam.org/files/file_attachments/bp-reward-work-not-wealth-220118-es.pdf 
Pérez-Castro, J. (2017). La ética académica en contextos laborales cambiantes. Praxis Sociológica, (22), 115-133. Última visita 2 de marzo de 2018. Recuperado desde http://www.praxissociologica. es/images/PDF/2017-22/praxis09-22.pdf

Perrenoud, Ph. (2004). Diez nuevas competencias para enseñar. Querétaro: Gráficas Monte Albán. Última visita 9 de julio de 2017. Recuperado desde https://www.uv.mx/dgdaie/files/2013/09/ Philippe-Perrenoud-Diez-nuevas-competencias-para-ensenar.pdf

Pinto, M. y Gálvez, C. (1996). Análisis documental de contenido: procesamiento de información. Madrid: Síntesis.

UNESCO (1998). La educación superior en el siglo XXI: Visión y acción. Informe Final de la I Conferencia Mundial sobre la Educación Superior. París: Organización de las Naciones Unidas para la Educación, la Ciencia y la Cultura. Última visita 28 de septiembre de 2016. Recuperado desde http://unesdoc.unesco.org/images/0011/001163/116345s.pdf

(2015). ODS 4: Educación de calidad. París: Organización de las Naciones Unidas para la Educación, la Ciencia y la Cultura. Última visita 12 de octubre de 2017. Recuperado desde http://www.un.org/sustainabledevelopment/es/education/

. (2017). Informe de seguimiento de la educación en el mundo 2017/8. París: Organización de las Naciones Unidas para la Educación, la Ciencia y la Cultura. Última visita 15 de agosto de 2018. Recuperado desde http://unesdoc.unesco.org/images/0026/002610/261016S.pdf

UWN (2018). Transformative leadership: ethical values. University World News. 29 january 2018. Última visita 23 de octubre de 2018. Recuperado desde http://www.universityworldnews.com/ index.php?page=Trans_Lead

Winfield, A. M. y Topete, C. (2014). Ética de gestión en instituciones de educación superior: dilemas morales. Revista Internacional de Organización Educativa y Liderazgo, 1(1), 45-64. Última visita 7 de abril de 2018. Recuperado desde http://journals.epistemopolis.org/index.php/ liderazgo/article/download/1077/640. 
